\title{
A cidade e o campo no nuevo cine argentino: Mundo grúa (1999) e a obra de Pablo Trapero
}

\section{Fábio Raddi Uchôa}

Pós-doutor em Imagem e Som pela Universidade Federal de São Carlos (UFSCar). Doutor em Ciências da Comunicação pela Escola de Comunicação e Artes da Universidade de São Paulo (ECA/USP). Professor adjunto do Programa de Pós-Graduação Comunicação e Linguagem da Universidade Tuiuti do Paraná (UTP/PR). E-mail: raddiuchoa@uol.com.br

\section{Débora Regina Taño}

Bacharel em Imagem e Som pela Universidade Federal de São Carlos (UFSCar) e mestranda pela mesma universidade. Tem como foco de pesquisa o cinema argentino contemporâneo e o som no audiovisual, área na qual também atua na prática. E-mail: debora.tano@gmail.com
Resumo: Este artigo questiona as presenças da cidade e do campo no nuevo cine argentino e, em particular, no filme Mundo grúa, de Pablo Trapero. Acompanhando uma das tendências do período, nas obras do diretor nota-se uma reformulação de tais espaços, gradualmente associada a uma ênfase aos interstícios da sociedade. Após debater as noções de cidade e campo nas ciências humanas e no nuevo cine, sua configuração em Mundo grúa será analisada em sintonia com a noção de paisagem, que abrange as relações estabelecidas entre personagens e espaços, bem como a coexistência de referenciais narrativos em práticas de fronteira. No filme em questão, nota-se um cotejo particular entre a tendência documentarizante, os fragmentos do road movie e uma construção criativa de não lugares, que aqui colaboram para a união da cidade e do campo como espaços de exploração do operário, com algum vislumbre utópico.

Palavras-chave: Nuevo cine argentino; Pablo Trapero; A cidade e o campo.

The city and the countryside in the new Argentine cinema: Crane world (1999) and Pablo Trapero's work

Abstract: This article questions the presence of the city and the countryside in the new Argentine cine, and particularly in the movie Crane world, by Pablo Trapero. In line with one of the tendencies of the period, in the director's works is evident a reformulation of such spaces gradually associated with an emphasis on the interstices of society. After discussing the notions of city and field in the humanities and in the nuevo cine, their configuration in Crane world will be analyzed in line with the concept of landscape, which covers the relations between characters and spaces, as well as the coexistence of narrative frameworks in border practices. In the movie, there is a particular coexistence of the documentary trend, the road movie fragments and a creative construction of non-places, which contributes to join city and countryside as spaces of worker exploitation, with some utopian glimmer.

Keywords: New Argentine cinema; Pablo Trapero; City and countryside. 
${ }^{1}$ Todas as citações deste estudo foram traduzidas para o português pelos autores do artigo.

\footnotetext{
${ }^{2}$ Entendemos aqui por

"documentarizante" um tipo de leitura realizada pelo espectador, a quem, em algumas das passagens do filme, sugere-se tomar a câmera e a sociedade na qual o filme se insere como enunciadores reais, colocando-se como modalidade particular daquilo que Roger Odin denomina "leitura documentarizante" (ODIN, 2012).

${ }^{3}$ Jens Andermann aborda tal tendência à espontaneidade a partir do termo "naturalismo" (ANDERMANN, 2015: 117).

${ }^{4}$ Termo inspirado no debate do "uso criativo da realidade" de Maya Deren (2012).
}

${ }^{5}$ Filme composto por curtas dirigidos por Daniel Burman, Adrián Caetano, Jorge Gaggero, Tristán Gicovate, Sandra Gugliotta, Paula Hernández, Lucrecia Martel, Pablo Ramos, Ulises Rosell, Bruno Stagnaro e Andrés Tambornino.

\section{Introdução}

O primeiro longa-metragem de Pablo Trapero, Mundo grúa, reverbera traços da cinematografia do nuevo cine argentino e da posterior obra do cineasta. Além disso, o filme possibilita examinar as construções da cidade e do campo, bem como do estilo dos filmes do diretor e roteirista argentino. Realizado em Buenos Aires e na província de Comodoro Rivadavia, Mundo grúa faz parte da produção que acompanha a crise econômica e social argentina da segunda metade dos anos 1990, que se iniciou no governo de Carlos Menem (1989-1999) e atingiu seu ápice em 2001. Observa-se nesse período uma considerável mudança nas construções do campo e da cidade no cinema argentino, paralelamente às reconsiderações sobre as identidades argentinas presentes na heterogênea produção audiovisual do período, conhecida sob o rótulo de nuevo cine argentino. Num contexto de reverberações da débâcle argentina, buscando-se ultrapassar o enfoque de uma transposição tal qual da crise e da pobreza às telas, pode-se tomar Mundo grúa como local privilegiado para pensar a cultura do período, devido a sua natureza de reestetização perante a realidade socioeconômica do período. Construído como lócus de "todos os outros imagináveis" entre o imaginário e o despertar (COMOLLI, 1997: 159), o filme possui um "ponto de vista diferencial" ${ }^{1}$ (ANDERMANN, 2015: 15) que passa pela construção dos espaços do campo e da cidade.

Mundo grúa trata da história de Rulo, um trabalhador da construção civil que fora músico em sua juventude. Ele vive com seu filho, também músico, e está iniciando um novo trabalho como operador de gruas em Buenos Aires. Um problema de saúde, no entanto, faz que não possa seguir essa ocupação. Logo consegue uma indicação para outro serviço em Comodoro Rivadavia, no sul do país, onde depara com as difíceis condições colocadas aos trabalhadores e as consequências de um capitalismo em crise. Sua história apresenta o deslocamento de um trabalhador da capital para o interior, sugerindo uma forma particular de encarar essa relação entre as regiões do país.

No filme, assim como em outras obras de Trapero, o lugar e a paisagem em que se desenvolvem as ações estão intimamente relacionados a estas, uma vez que a vida e a construção dos personagens se ligam ao lugar que habitam. Eles não apenas ocupam um espaço, mas são formados por ele, chegando até mesmo a alterá-lo, como é o caso de Rulo, que nas duas cidades onde vive as altera e é alterado por elas. Essa relação pode ser entendida de diversas formas. $O$ primeiro longa de Trapero também possui pontos de contato formais com outros de seus filmes, incluindo uma tendência documentarizante ${ }^{2}$ proveniente da alteridade dos espaços e personagens marginais enfatizados ${ }^{3}$, as reminiscências do road movie, bem como uma construção criativa de não lugares ${ }^{4}$. Para examinar a construção do cidade-campo, Mundo grúa será explorado como paisagem, em termos de um espaço significado, sugerindo o visível sob o viés do cinema num contexto de decadência socioeconômica, e, por outro lado, em termos de uma prática de fronteira, que reprocessa fazeres cinematográficos, em diálogo com experiências do período.

\section{A obra de Trapero, o campo e a cidade}

Pablo Trapero é diretor, roteirista e produtor argentino que teve sua carreira iniciada com o curta-metragem Negocios, um dos escolhidos para compor o longa Historias breves (1995)5. Entre os seus - até o momento - oito longas-metragens, além de outros curtas e segmentos de filmes como 7 dias en la Havana, Trapero aborda de forma recorrente o espaço urbano, incluindo visitas e trânsitos ao mundo rural.

Os quatro primeiros - Mundo grúa (1999), El Bonaerense (2002), Familia rodante (2004), Nacido y criado (2006) - recorrem ao campo, ou, ao menos, a cidades vizinhas à metrópole, a partir de diferentes formas e visões. Enquanto em 
Mundo grúa, como tratado, o interior do país é um local de extensão da exploração que ocorre na cidade, em El Bonaerense o personagem sai de sua cidade, que fica bem próxima a Buenos Aires, para enfrentar o mundo policial na capital. De forma diversa, Familia Rodante leva os onze integrantes da família da capital à fronteira com o Brasil para um casamento, sendo a viagem e, portanto, também o interior, uma forma de representação do contato com as origens familiares, bem como dos descompassos pessoais atuais entre seus membros. Nacido y criado, por sua vez, também tira o personagem central da capital e o leva às paisagens frias e vazias da Patagônia para fugir de sua antiga vida depois de uma grave tragédia. É possível notar que enquanto nos dois primeiros filmes a locomoção e a mudança entre campo e cidade se dão por condições sociais e de trabalho, os dois últimos colocam a paisagem como projeção dos personagens, como visão externa de suas buscas pessoais ou relacionais.

Já os outros quatro filmes são predominantemente urbanos. Com exceção do mais recente, El Clan, de 2015, baseado em uma história verídica do país e que trata da classe alta, os outros - Leonera (2008); Carancho (2010); e Elefante Blanco (2012) - colocam seus personagens em não lugares sociais e físicos. Leonera trata de uma mulher que é presa grávida e de sua vida com o filho na cadeia. Após alguns anos, a briga entre ela e a mãe pela tutela do garoto faz que, em uma de suas saídas, a personagem fuja com o filho em direção ao interior e posteriormente ao Paraguai para terem uma vida juntos. Carancho acompanha as ações de um advogado que se aproveita de vítimas de acidentes de trânsito e uma médica que atua em primeiros socorros. A relação dos dois se dá em meio aos golpes efetuados por ele, os acidentes e o hospital onde ela trabalha, numa ligação com a violência moral e física da cidade. O não lugar em que habitam os personagens dos filmes de Trapero fica ainda mais marcante em Elefante Blanco. Em uma construção paralisada de um antigo hospital vive toda uma comunidade de pessoas em subcondições. Os personagens centrais, dois padres e uma assistente social, tentam defender a vida e os direitos daqueles cidadãos que se encontram à margem da cidade de Buenos Aires em todos os sentidos.

Tais filmes, cada um a sua maneira, agregam traços próprios ao cinema argentino da época e do cinema de Trapero em geral. Entre tais traços, que terão configuração particular em Mundo grúa, pode-se colocar em pauta a representação da pobreza, associada a certo tom documental - denominado por Joanna Page (2009) de arqueologia do presente, que é relacionada à observação de personagens que não têm domínio de seu próprio destino, a partir de rupturas para relevar a espontaneidade e o lirismo do cotidiano dos excluídos. Em contato com outras produções do período, além dessas espontaneidades, os filmes de Trapero apresentarão reminiscências do road movie, com seu gosto por planos do ponto de vista dos passageiros, os pontos de abertura do roteiro, suas mesclas entre ficção e documentário, unindo também a atenção turística e os possíveis disparates da modernidade sobre o campo.

Outro dos traços consonantes, por fim, será o referido gosto por não lugares físicos e sociais, construídos pela reincidência de corpos e elementos narrativos em espaços diferentes, mas também pelo local social dos personagens, às margens da pobreza e do não visível. Nesse sentido, o não lugar aqui pensado não equivale ao conceito homônimo, associado por Marc Augé (1994) a espaços de trânsito (autoestradas, supermercados, centros comerciais, aeroportos etc.), próprios à cidade na hipermodernidade. Esses espaços opõem-se à cidade tomada como lugar do encontro, bem como à importância das fronteiras na definição da identidade e das condutas sociais. Ao contrário, o não lugar físico e social dos filmes de Trapero, com particular ênfase a Mundo grúa, refere-se, muito mais, ao olhar que se volta à marginalização e a suas implicações sobre as reconstruções imaginárias da nação argentina entre as décadas de 1990 e 2000. Em termos temáticos e culturais, trata-se de uma mirada que reverbera o grande estrato, 
fragmentário e intersticial, de subempregados urbanos, típicos da sociedade argentina na passagem ao século XXI, cujas fissuras, segundo Beatriz Sarlo (2001), decorrem do imaginário midiático e da decadência de laços de sociabilidade. A isso acompanha um ato cinematográfico em si intersticial, unindo, em diferentes cotejos, o gosto pela espontaneidade documental, os fragmentos do road movie, bem como a tematização de populações de bordas da sociedade argentina.

\section{Campo e cidade no nuevo cine argentino}

Para entender o cinema de Pablo Trapero na passagem entre os anos 1990 e 2000, deve-se levar em conta, em termos de consonância históricocinematográfica, o contexto da Argentina do período, bem como a retomada de Buenos Aires nas telas, processada por filmes do nuevo cine. Há muito a capital argentina era um lugar consolidado, onde pessoas formavam suas vidas e suas famílias e onde a economia acontecia, ou, como no caso, começaria a deixar de acontecer. Depois da inflação e da instabilidade política, marcantes durante o governo de Raúl Alfonsín (1983-1989), seu sucessor Carlos Menem assumiu o poder com a intenção de alçar a Argentina a um país de primeiro mundo. Em termos de política econômica, durante a década de 1990, houve a amenização da presença do Estado e a imposição de um sistema neoliberal. Sob a face de uma modernização fictícia, o governo de Menem (1989-1999) foi acompanhado pelo esfacelamento do setor produtivo e das empresas tradicionais, assim como pelo aumento do desemprego e dos níveis de pobreza no país. No final de 2001, com o debandar dos investidores financeiros, a recessão econômica aprofundou a corrida dos bancos, a queda do PIB e a grave desvalorização da moeda, eventos acompanhados por protestos populares e crise na produção de alimentos. Paralelamente a essa crise, a segunda parte dos anos 1990 será o berço de um grupo variado e por vezes díspar de obras e cineastas, que com o apoio da Ley del Cine (1994), a confluência de uma leva de novas escolas de cinema, além do trabalho com baixos orçamentos, será responsável por um boom na produção cinematográfica do país. Nesses filmes, as dificuldades socioeconômicas não serão o tema principal, embora as consonâncias políticas possam ser encontradas nos meandros das relações dos personagens entre si e com os espaços, entre campo e cidade, bem como na ambiguidade por vezes pessimista dos desfechos.

Tal como denominado pela crítica, o nuevo cine argentino - o cinema produzido na Argentina a partir de 1995 e da estreia do filme Historias breves - é assim conhecido por apresentar mudanças na forma de fazer cinema no país a partir de então. Rompendo com o cinema dos anos 1980 e suas narrações alegóricas em tentativas de explicar o país, os filmes desse período podem apresentar características comuns em suas temáticas, estéticas e formas de produção, por mais que não constituam propriamente um movimento. Sob o grande leque de filmes do período, enfatizamos aqui aqueles que colaboram com a reconstrução da cidade e do campo, com especial ênfase às obras de cineastas como Carlos Sorín, Bruno Stagnaro, Adrián Caetano, Lucrecia Martel, Fabián Bielinsky, Daniel Burmán e Pablo Trapero.

Entre tais características, pode-se destacar o interesse pelos interstícios da sociedade argentina, o gosto por uma espontaneidade na fotografia e na atuação, que por vezes flerta com o documental, bem como possíveis aproximações com o neorrealismo, em termos do trabalho com baixos orçamentos, a recorrência a atores não profissionais, a expressão eloquente das fissuras e imperfeições do presente (PAGE, 2009: 34). Num contexto de extravasamento da crise econômica, parte de tais filmes trazem às telas espaços e classes não visíveis pelo cinema hegemônico, mantendo-os, porém, como outros distantes, ou outsiders que circulam por zonas de exclusão social; espaços que podem ser aproximados daquilo que Beatriz Sarlo (2001: 114) denomina de uma "zona gris de deambulantes", ou daquilo que Castells propõe como "buracos negros do capitalismo informacional" 
(CASTELLS, 1998: 162). Trata-se, sobretudo, das primeiras aventuras de cineastas no campo do longa-metragem, compartilhando as heranças de uma Argentina pós-ditadura, a pesada marca autoral, os personagens bem construídos, uma encenação imaginativa, além de estratégias provenientes da experiência no campo dos curtas, do amador e do cinema independente. Apesar da política não se constituir como temática de proa, ela aparece denotando-se apenas indiretamente como o sintoma de um sistema perverso, num contexto que se encaminhava à crise econômica. A partir de David Oubiña (2004), pode-se pensar em um conjunto de obras que recolocam a impossibilidade da transformação a partir de um modelo recorrente, que do ponto de vista das ações dos personagens tende à não realização, havendo "sempre os mesmos elementos e o mesmo conjunto limitado de funções" (Ibid.).

Entre as características de interesse para este artigo estão a forma de apresentação da paisagem e seus desdobramentos na construção da cidade e do campo no cinema. São perceptíveis transformações quanto ao contexto geográfico no qual os filmes de Trapero e do nuevo cine aqui abordados se passam, além da alteração, algumas vezes, do próprio lugar de filmagem, que deixa a capital do país para alcançar outras regiões. Em alguns casos, nota-se a busca por novos eixos, extrapolando a centralidade da capital Buenos Aires, e o estudo, de diferentes formas, de paisagens físicas e humanas pouco habitadas pelo cinema nacional até então, seja ao norte ou ao sul. Além desse ponto, os filmes do período, de forma geral, prezam pelo coloquialismo dos personagens, aproximando-os de pessoas reais, menos tipificados se comparados às produções anteriores.

Pode-se pensar numa nova maneira de estar e ocupar o urbano, com uma tendência mais simbiótica entre a construção física da cidade e a existência social e afetiva dos personagens. Tendo como marco inaugurador o filme Pizza, birra, faso (de Adrián Caetano e Bruno Stagnaro, 1999), considerado o primeiro longa do período - uma vez que Historias breves é uma coletânea de curtas-metragens -, o nuevo cine se coloca efetivamente dentro da capital argentina. O filme de Caetano e Stagnaro apresenta um grupo de jovens desempregados, que vive da prática de pequenos assaltos, numa cidade predominantemente noturna e de dejetos, incluindo as entranhas de regiões centrais, avenidas, terrenos baldios, espaços de docas, bem como perseguições de carro sob as luzes da Buenos Aires turística e de becos salubres. Os personagens não apenas estão ali, atuando sobre um espaço, mas ocupam, interagem, vivem daquele lugar e sob uma ética do banditismo inerente a tal sobrevivência. Os jovens de Pizza, birra, faso agem, andam e se alimentam pelas ruas; se relacionam nelas e com elas; habitam pontos turísticos - como o famoso obelisco -, mas agora por dentro da construção e não apenas olhando-a; vivem e morrem de acordo com o andar sobre a cidade à qual estão intimamente ligados. Em termos formais, há uma coexistência de tendências: uma tendência espontânea, presente no despojamento dos atores e na captação por vezes documental dos espaços e movimentos dos transeuntes, que caminha ao lado de uma tendência de inspiração no gênero policial, com os assaltos, trocas de tiros e perseguições policiais. A partir do viés do migrante absorvido em trabalhos precários, o filme Bolivia (2001), também de Caetano, recoloca o interesse pelos interstícios da cidade e da sociedade argentina num contexto de crise econômica. A cidade é, aqui, um campo de confronto cotidiano de Rosa e Freddy com o chefe, os clientes e a própria polícia. O olhar versa

${ }^{6}$ Para Joanna Page (2009: 63), em Bolivia descobre-se um potencial lírico do cotidiano e dos objetos, trazendo consigo um posicionamento artístico perante a crise política e social. Busca-se uma estética que possa aproximar a tragédia e a experiência humana, explicando também a confusão de uma existência à sombra da lei ou à beira da ruína. predominantemente sobre as ações diárias desses trabalhadores clandestinos, que não conseguem uma efetiva inserção junto à cultura e ao mercado de trabalho legal argentinos, restando como não cidadãos. São párias legalmente desprotegidos e socialmente discriminados, por gestos, olhares, atos falhos, ou até embates corporais que levarão ao assassinato de Freddy. Em Bolivia, a construção formal apresenta Buenos Aires como uma fronteira cultural. Por um lado, nota-se um afã documental, fundado no lirismo do cotidiano do bar, na documentação de seus espaços, utensílios, gestos e frequentadores ${ }^{6}$. A seleção 
dos atores e sua atuação contida sugerem certo despojamento, que se apresenta a partir de uma leitura com tendência documentarizante. Por outro lado, a trilha musical evoca constantemente a presença cultural boliviana, outro tempo-espaço que por vezes se sobrepõe às imagens com tendência documental.

Assim como os jovens de Pizza, birra, faso ou os migrantes de Bolivia, estão os golpistas de Nueve reinas (Fabián Bielinsky, 2000), o policial de El Bonaerense (Pablo Trapero, 2002), o jovem descendente de poloneses de El Abrazo Partido (Daniel Burmán, 2005), ou o operário de Mundo grúa (Pablo Trapero, 1999) que será aqui debatido, entre tantos outros que têm na cidade a base de referência narrativa para as ações e acontecimentos de suas vidas. Todos eles poderiam ser pessoas reais que verdadeiramente habitam essa cidade, ocupando cada um seu não lugar, lugares não vistos, não reconhecidos, mas tão importantes para o funcionamento da vida urbana como qualquer outro. A cidade, portanto, é mostrada a partir da realidade dos personagens e não de forma idealizada, deixando de ter o papel de fundo, de cenário e passando a influenciá-los diretamente ou, até mesmo, sendo um deles.

Já no que se refere ao contato com o interior, as abordagens podem ocorrer de formas distintas, seja em uma intenção apaziguadora e de resgate das origens, numa busca pelo nacional; seja sob a ótica do trabalho, da impossibilidade perante os entraves causados pela economia e pela política do período. Independentemente da abordagem, o ir ao interior, retratá-lo, usá-lo como base para esses personagens e, além disso, levar a própria produção cinematográfica a esses locais é uma das inovações realizadas pelos cineastas do nuevo cine.

Isso está presente, por exemplo, nos filmes de Lucrecia Martel, que cria suas histórias baseadas no lugar onde viveu, a província de Salta, a noroeste do país. Assim, em La ciénaga (2001), o campo associa-se às figuras da piscina e do pântano, colocando-se como espaço do tédio e das enfermidades familiares. O tema clássico da família burguesa é retomado com flertes experimentais, sobretudo a partir do fermentar dos corpos e espaços, da atmosfera de abafamento, bem como dos incômodos sonoros, que estão na base de uma narrativa de total negação do progresso e da cidade como seu núcleo depositário. Há também os filmes de Carlos Sorín, como Historias mínimas (2002) e El camino de San Diego (2006). No primeiro, filmado na província de Santa Cruz, na Patagônia, o urbano corresponde a uma presença fragmentar, pela TV, pelo telefone e por esparsos produtos industrializados. A narrativa concentra-se no deslocamento de três personagens em direção a San Julian, num jogo onde o citadino equivale às inconstâncias e aos objetivos sem sentido. Trata-se de um road movie, cujos trânsitos mimetizam uma fuga entre o vazio das planícies rurais e o absurdo das comodidades modernas citadinas. Já em El camino de San Diego, o personagem sai da província de Misiones, ao norte, e se dirige à capital a fim de levar uma raiz esculpida para Maradona, seu ídolo que está doente. As tradições rurais estão presentes nas fisionomias e na sociabilidade, colocando-se como uma das bases da narrativa, por meio da projeção do humano sobre a natureza e os desdobramentos disso como crença na possibilidade de cura. O longo trajeto, entre Misiones e Buenos Aires, apresenta os confrontos e disparates entre rural e modernidade, com a gradual presença de objetos industrializados - processo este incorporado pelo próprio personagem: um indígena com a camisa da seleção argentina. Ambos os filmes de Sorín são construídos a partir da tendência de uma filmagem próxima ao documental, que coloca pessoas locais e suas formas de fala e vida em contato com os personagens centrais. As histórias se mesclam entre o ficcional e algo muito próximo do real próprio de cada localidade. Entre outras possibilidades de construção do campo e da ruralidade, há ainda os filmes de Pablo Trapero, nos quais o campo assume diferentes articulações com a cidade, sendo desdobramento da exploração urbana como em Mundo grúa, que será aqui debatido, ou então, depositário de uma busca pelas relações familiares e pessoais, como em Familia rodante (2004) e Nacido y criado (2006). 


\section{Sintonias metodológicas: o campo e a cidade, a noção de paisagem}

Se o nuevo cine argentino e a filmografia de Trapero colaboram para remodelar as relações entre cinema, cidade e campo, tal debate faz parte de um longo caminho traçado por autores da sociologia, da literatura e do próprio cinema, como Henri Lefebvre, Raymond Williams e Jean-Claude Bernardet, que nos auxiliam com uma fortuna teórica de base para pensar o fenômeno.

As relações entre campo e cidade, bem como suas apropriações pelas artes, assumem diferentes configurações de acordo com os contextos sociais e teóricos envolvidos. Na sociologia de Lefebvre, por exemplo, pode-se pensar nas noções de rural, industrial e urbano como formas de organização que concentram em si resíduos e coexistências de diferentes temporalidades e relações sociais. No caso do rural, trata-se da comunidade, de homens com fraquezas perante a natureza, unidos a partir de disciplinas e propriedades coletivas (LEFEBVRE, 1978: 72). O industrial, por sua vez, desdobra-se da gradual subordinação da produção agrícola à concentração dos meios de produção, bem como à criação de uma "imagem da cidade" (Id., 1999: 22) que se interpõe entre homens e natureza. No final do túnel, o urbano coloca-se como um terceiro estágio, um objeto utópico que pressupõe a realização das potencialidades de humanização. Em tal contexto, haveria a superação das oposições entre campo e cidade, a partir de um processo de implosão-explosão e a mistura entre o passado e o possível. Esse projeto de identificação e superação do fragmentar, presente enquanto formulação teórica e ação narrativa, coloca-se como interessante caixa de ecos para o reprocessar das polaridades campo-cidade no nuevo cine e, especialmente, para a união explosiva, proposta por Mundo grúa a partir da união de espaços e referenciais narrativos também fragmentares.

No campo da literatura, as diferentes configurações assumidas por esses espaços devem levar em conta o trabalho de Raymond Williams, para quem a cidade, o campo e suas inter-relações são realidades históricas em transformação. Entre as categorias de A cidade e o campo: na história e na literatura, o crítico inglês identifica um tipo particular de literatura, situado entre a escrita urbana e a rural, composto por obras atentas aos trânsitos e fronteiras entre tais espaços, redigidas sob os ecos das transformações da Revolução Industrial. Aproximando-se da natureza desses materiais, Mundo grúa de Trapero propõe uma reconstrução do campo e da cidade permeada pela atenção aos interstícios, colocando-se como uma obra atenta às fronteiras num período de crise socioeconômica. É possível que essa formulação explicite uma "experiência social em solução" (WILLIAMS, 1979: 134), ou uma formulação ainda sem forma social definitiva e compartilhada, em suas diferentes variações, por parte de uma geração de artistas.

Voltando-se ao universo da sétima arte, Jean-Claude Bernardet (1980) realizou um importante estudo sobre essas relações no cinema brasileiro que possibilita inspirações de abordagem para o estudo de Trapero no contexto da produção argentina do nuevo cine. Como sugerido pelo crítico, seria possível acompanhar as transformações formais e ideológicas da construção do eixo cidade-campo no contexto de cinematografias específicas. Trata-se de uma temática já presente na literatura e no teatro, que é posteriormente transposta ao cinema, onde suas nuances passam a reverberar as transformações socioculturais e do olhar construído por aqueles que filmam. Entre as categorias sugeridas por Bernardet ao longo do cinema do século XX, encontramos: a construção da relação campo/cidade sob a chave da preservação/dissolução da moral; a exaltação da euforia e da agitação urbana, com a omissão do espaço campesino; ou então, a cidade marcada pela experiência da migração, um espaço sociologicamente negativo que massacra e rejeita o operário ${ }^{7}$. Essa última modalidade, criada por Bernardet para questionar filmes como Zézero (1976), de Ozualdo Candeias, resguardados os devidos ajustes, parece adequada para pensar os tipos físicos e humanos intersticiais do cinema

${ }^{7}$ Tais configurações, entre outras sugeridas por Bernardet, apesar de dizerem respeito ao contexto do cinema brasileiro do século XX, podem ser identificadas em outros cinemas e outras artes, como o caso da literatura inglesa trabalhado por Raymond Williams (1989), na qual pode-se identificar paralelos, em termos dos matizes assumidos pela cidade e pelo campo. 
de Trapero e, especialmente, em Mundo grúa, num contexto em que ambos os espaços, campo e cidade, parecem expulsar o trabalhador.

Para além dos aportes da fortuna teórica sobre o campo-cidade, as coexistências temáticas e narrativas, presentes em parte dos filmes aqui debatidos, permitem diálogos com a noção de paisagem, proveniente da Geografia Humana, e que se coloca como índice inspirador para essa análise.

Nas obras de Trapero e dos então jovens realizadores do nuevo cine é possível perceber que tanto a capital quanto o interior tiveram suas imagens alteradas. Tendo a paisagem física como uma personagem, um fator determinante e não apenas pano de fundo, as narrativas parecem se apropriar de seus contextos, de seus locais de produção e narração, aprofundando a relação entre o filme e o que o circunda. Por outro lado, pode-se pensar nesses filmes, em si, como paisagens, que agregam diferentes referenciais narrativos, variadas reminiscências daquilo que é visível no contexto argentino de então, bem como articulam práticas de fronteira, em termos culturais, cinematográficos e dos cotejos entre o rural e o urbano. Nessa senda, a noção de paisagem será aqui adotada a partir de uma reconceituação que abrange configurações diegéticas (personagens, trânsitos e espaços), mas também traços extradiegéticos, do cinema como prática narrativa de fronteira (referenciais cinematográficos, identidades e configurações do visível, num contexto socioeconômico particular).

Para tanto, deve-se levar em conta as reverberações do trajeto do conceito de paisagem, que se consolida no campo da Geografia Humana, para referir-se aos fenômenos que são ao mesmo tempo físicos, enunciativos e culturais, remontando à noção de desenvolvimento desigual e combinado. Para Ana Fani Carlos (2004: 33), trata-se de uma obra coletiva, contemplando todas as dimensões humanas (sentidos, cheiro, tátil, visão, afetos), capaz de representar as contradições das forças produtivas em determinado contexto histórico, sendo cheia de vida e história, presente e passado.

No debate recente, a noção será transposta aos estudos do audiovisual, remetendo-se a aspectos interculturais e fronteiriços da arte cinematográfica. Assim, pode-se levar em conta a proposta de Denilson Lopes, em "Paisagens transculturais", em seu diálogo com a noção de "entre lugar", a partir de Silviano Santiago, tomando forma de redefinir a nação e questionar as hierarquias internacionais (LOPES, 2010). Andréa França (2002) também se preocupa com o cinema em contextos de redefinição das noções de nação. Assim, examina a noção de fronteira, considerando as relações mantidas pelo cinema com o espaço, tratando-se aqui não de fronteiras físicas ou geográficas, mas das referências imaginadas pelo cinema, inserindo-se "entre aquilo que diz respeito a um estado de coisas (histórico-social), e aquilo que é materialidade sensível, formada e determinada" (Ibid.: 61) No contexto dos filmes aqui debatidos, com especial ênfase ao cinema de Trapero, estamos tratando de modalidades de desenraizares, bem como de redefinições das fronteiras imaginárias, seja no contexto diegéticonarrativo, seja em termos da inserção e do debate social presente em suas obras. Tratamos, assim, das redefinições do cinema enquanto forma de narrar, significar e realizar, num contexto de crise do capitalismo, paralelamente a uma redefinição do visível e das construções do rural e do urbano.

Colaborando para questionar as configurações da cidade e do campo no nuevo cine, Jens Andermann mapeia os filmes do período a partir de seu ponto de vista diferencial ante a crise argentina, onde "o que está em jogo são diferentes estratégias de refração e mise en scène que têm por objeto fazer reconhecível a diferença e o caráter diverso da imagem cinematográfica em relação à realidade contemporânea" (ANDERMANN, 2015: 15). A cidade será tomada 
${ }^{8}$ Andermann inicia a chave urbana de filmes com destaque a Pizza, birra, faso (1997), de Adrián Caetano e Bruno Stagnaro.

${ }^{9}$ El hijo de la novia (2001) e Luna de Avellaneda (2004), de Juan José Campanella.

${ }^{10}$ Vagon fumador (2001), de Verónica Chen; Ronda nocturna (2005), de Edgardo Cozarinsky.

${ }^{11}$ Bolivia (2001), de Adrián Caetano; Copacabana (1999), de Martín Rejtman; Habitación disponible (2005), de Eva Poncet, Diego Gachassin e Marcelo Burd.

${ }^{12}$ Dentre a chave rural, Andermann incluirá filmes de Pablo Trapero (Mundo grúa, Familia rodante, Nacido y criado), Sandra Gugliota (Las vidas possibles), Mariano Donoso (Opus), Lucrecia Martel (La ciénaga), Albertina Carri (La rabia) e Alonso (La liberdad, Los muertos, Liverpool).

\footnotetext{
${ }^{13}$ Em espanhol, usada para referir-se ao guindaste, mas também para a grua cinematográfica.
}

como local-chave da crise, incorporando diferentes jogos entre as texturas do real e o distanciamento crítico, com a identificação de tendências gerais como: a apresentação das margens e dos excluídos da modernidade neoliberal, a partir de seus interstícios ${ }^{8}$; a representação da decadência a partir do universo da classe média9; a apresentação da cidade como um espaço erotizado e mercantil, tomada como palco para o espetáculo da mercadoria e de realidades noturnas múltiplas ${ }^{10}$; bem como a cidade em trânsito, proporcionada por experiências migratórias $^{11}$. O campo, por sua vez, é abordado pelas presenças da paisagem, como espaço narrativo aberto a inscrições alegóricas, e, ao mesmo tempo, como experiência puramente estilística que excede o diegético, unindo também as irrupções fragmentares do road movie, do melodrama rural e de uma tendência documentarizante que emerge da alteridade dos espaços marginais ${ }^{12}$. É nesse contexto que se inserem os filmes de Trapero e Mundo grúa, incorporando diferentes vertentes de traços elencados por Andermann, e se colocando como um cinema de interstícios, em termos temáticos e das coexistências de linguagem.

\section{Mundo grúa (1999): a não inclusão e o campo como extensão da exploração urbana}

É nessa situação, de uma vida econômica em dificuldades, de uma cidade que se mantém por meio do trabalho de operários e pequenos comerciantes, que se insere a história do protagonista de Mundo grúa. Rulo é um operário em busca de emprego, inicialmente na cidade e depois no campo. Entre sua inserção como manobrista de guindastes na construção urbana em Buenos Aires e seu desdobramento como operário na longínqua cidade de Comodoro Rivadavia, acompanhamos o relato do cotidiano das classes médias baixas argentinas, com suas ocupações passageiras, numa constante busca por inserir-se no mercado ou consertar mecanismos obsoletos. O tom geral é nostálgico, sempre se valendo da construção grandiosa do passado, diante de um presente decadente. Ao acompanhar o personagem Rulo, a narrativa de Mundo grúa sugere um trajeto onde a cidade e o campo repelem a presença do operário, embora unidos pelo gesto de apropriação do mundo pelo personagem. A cidade é o ponto inicial do trajeto daquele que não encontra lugar, em termos de relações pessoais e de trabalho.

A palavra "grua", por sua vez, contemplando o acúmulo de gesto laboral e gesto artístico ${ }^{13}$, levando-se em conta seus desdobramentos narrativos, é central para se pensar no filme de Trapero. Na construção urbana, a grua equivale aos desdobramentos de um movimento gravitacional e circular, deslizando pelos céus e horizontes da cidade. Trata-se de um gesto social, reprocessado e reconstruído, da liberdade do operário em posse de seu instrumento de trabalho. A partir de uma utopia incipiente, que logo será anulada, Rulo tem momentaneamente o poder para projetar a própria vida, em termos pessoais e profissionais. A possibilidade do emprego lhe permite um apropriar-se criativo do céu portenho, com a passageira utopia do planejar a cidade e a si mesmo, posse transitória do corpo humano e do corpo da cidade. Já na província de Comodoro Rivadavia, a posse do guindaste por Rulo equivale à união com o coletivo de operários, que se organiza de maneira politizada, para opor-se à exploração do chefe. A não integração associa-se à consciência de si, num contexto em que o corpo impõe seus limites, sugerindo o trabalho como atividade perigosa. O mecânico remoer da terra, na longínqua Comodoro Rivadavia, substitui os anteriores movimentos circulares sobre o céu. A construção fílmica da grua deixa de lado os movimentos circulares e contínuos, aproximando-se, cada vez mais, de composições fragmentares, resíduos de uma atividade anteriormente utópica, fósseis marinhos em um espaço desertificado.

Ao lado do gesto da grua, como forma de apropriação de si e do mundo que une campo e cidade, inicialmente pela liberdade e depois pelo perigo, Mundo grúa caracteriza-se como um todo, na qualidade de uma paisagem fragmentar de tempos, espaços e linguagens. No plano das motivações de Rulo, o mundo se 
divide entre o presente deteriorante do desemprego e o glorioso passado como músico; trata-se de um presente como fossilização de vidas passadas, simbolizado pela paisagem de Laguna Seca, visitada por Rulo e seus amigos no final do filme. Paralelamente, Mundo grúa propõe experimentações intermediárias entre o documental e o ficcional, dialogando com filmes como Bolivia (2001).

Coexistindo com as ações encenadas, a tendência documentarizante advém da seleção dos espaços, dos tipos físicos e, sobretudo, do gosto quase documental pelo cotidiano das classes baixas e seus espaços de vivência. Assim, a Buenos Aires de Mundo grúa une canteiros de obra, pequenos comércios e módicas habitações periféricas. Ganham pregnância na memória do espectador o prédio em construção, com seu térreo repleto de dejetos, as escadarias e a cobertura com andaimes, ou então, a módica loja de sanduíches, com sua porta de ferro rodante, que será reparada por Rulo. Na região de Comodoro Rivadavia, por sua vez, apresentada como extensão da exploração urbana, predominarão os cômodos coletivos de operários, as obras a céu aberto e suas dificuldades cotidianas, que são apresentados de modo quase didático. Logo de sua chegada, o espectador acompanha o protagonista em sua visita quarto a quarto, verificando operários e desocupados pelo chão, incluindo uma visita a um banheiro com encanamentos expostos. No canteiro de obras urbano e, com maior ênfase, nos espaços de trabalho e descanso rurais, há trechos que poderiam ser tomados como documentários encenados, inseridos de maneira coerente com o conjunto ficcional mais amplo do filme. Trata-se de brechas quase invisíveis, unindo didatismo e denúncia social sob a roupagem ficcional.

Mundo grúa parece apresentar-se, assim, como uma série de paisagens da não inclusão, compostas por coexistências espaciais, temporais e de linguagem particulares. Nele, a tematização de uma Argentina decadente, recortada por deslocamentos humanos que não encontram integração, coexiste com a criatividade de Pablo Trapero, estampando a ação cinematográfica como apropriação utópica de uma temática do desconsolo.

Em Mundo grúa, a sobreposição de espaços cidade-campo é construída pela montagem, com a presença das mesmas ações e objetos em espaços diferentes, num processo que iremos denominar de construção criativa de não lugares. Trata-se de um possível desdobramento daquilo que Maya Deren teoriza como uma manipulação do espaço-tempo, figurando um uso criativo da realidade. Em seu artigo "Cinema: o uso criativo da realidade", a cineasta americana propõe que a manipulação dos tempos e espaços pode colaborar para a "criação de uma relação entre tempos, lugares e pessoas separados" (DEREN, 2012: 147). Um dos desdobramentos dessa ideia é que "Lugares distantes e separados podem não apenas ser relacionados, mas podem se tornar contínuos por uma continuidade de identidade e movimento" (Ibid.: 147). Mundo grúa, a seu modo, propõe um desdobramento de tal manipulação do tempo-espaço, em que a memória dos movimentos, temas e presenças físicas é reafirmada, com suas variações e diferenças, na cidade e no campo. A não inclusão do personagem na sociedade, bem como a criação de um não lugar, desdobra-se da sobreposição dos mesmos corpos e ações em espaços diferentes. Não se trata de um atributo dos espaços em si, mas do acúmulo de presenças formais, físicas e temáticas. Tal prática, envolvendo as reminiscências temático-formais entre diferentes espaços, parece ter desdobramentos em outros dos filmes de Trapero, como Familia rodante (2004), por exemplo.

Em Mundo grúa, tal prática sugere continuidades e diferenças entre cidade e campo. Ambos os espaços apresentam-se como não acolhedores à inserção social de Rulo, cujo destino sugerido é o constante trânsito, sendo a própria cidade um polarizador inicial. O campo, avesso a qualquer tratamento bucólico ou de retorno desejado às origens tradicionais, é apresentado como desdobramento 
da exploração presente na cidade. O descumprimento dos possíveis direitos trabalhistas, presente em Buenos Aires, é superado pela união dos operários no campo, a partir de uma consciência que também os afasta do trabalho em condições precárias. Em termos da construção do personagem, por outro lado, as continuidades temático-formais coincidem no trato de um operário inserido na paisagem e nos ambientes de trabalho dos quais faz parte. Ainda que enquanto desejo de apropriação de si e de seus meios de trabalho, Rulo apresenta-se como extensão dos guindastes, na cidade ou no campo. No primeiro caso, na modalidade de utopia libertadora, sobre a qual reverbera a amplitude das panorâmicas iniciais, mimetizando um olhar que se apropria de uma cidade desejada. No segundo caso, na qualidade de um corpo doente, extensão que remói a terra, matéria que guarda em si transformações e mortes naturais, sob a figura da Laguna Seca, um mar desertificado com algum potencial de presentificação do passado.

Em Mundo grúa, os traços do road movie coexistem com o surgimento de tais planícies, por vezes desérticas, sobre as quais projetam-se a solidão e a não inserção do personagem Rulo, com alguma reminiscência utópica, da magnitude de um passado mineral que se sobrepõe a um presente sem raízes ou inclusão. São passagens dispersas, especialmente associadas ao percurso de Rulo em direção à Laguna Seca, ou em seu deslocamento final em direção à cidade. Nessas passagens, com a construção de paisagens que envolvem trânsitos físicos e temporais, despontam preferências temáticas e formais que terão depuração posterior, em Familia rodante. Tratamos aqui, em termos narrativos, da manutenção de formas e temas ao longo dos diferentes espaços percorridos por personagens que transitam entre a cidade e o campo. Entre tais traços: o reflexo do retrovisor, as paisagens externas em movimento, bem como as internas do próprio veículo aderindo à tensão dos olhares ou ao vislumbre dos skylines em movimento. A referência a Familia rodante (2004) estipula um debate a ser aprofundado acerca do próprio road movie como forma de construção criativa do não lugar, associado ao trânsito entre campo e cidade, no âmbito da obra de Trapero. Sob esse viés, duas formas de construção do não lugar explicitam-se de antemão. No filme de 2004, nota-se um espaço intermediário, interno e externo, entre campo e cidade, tendo por vetor a pureza do retorno ao rural que coexiste com certa ruptura e conflito da estrutura familiar - traço este intensificado no cinema argentino na década de 1990, como apontado por Verardi (2007). Já em Mundo grúa, as reminiscências do road movie despontam em momentos de fuga perante a exploração vivenciada, seja no campo, seja na cidade. A mobilidade do olhar sugerida em tais passagens na província do país parece rimar com a liberdade da panorâmica que desliza sobre o skyline de Buenos Aires no início do filme, dando um laço final não destituído de utopia. Ao aproximar, simetricamente, a liberdade dos movimentos da grua urbanos e a fuga, própria aos movimentos espaciais do road, Mundo grúa sugere a própria superação da oposição campocidade e da exploração associada a tais espaços. Essa superação, porém, é fugaz e ambígua, unindo intuitivamente o desejo de liberdade e o peso da situação de não inclusão.

Ao cabo da análise, aqui realizada com Mundo grúa, pode-se considerar a importância narrativa, própria à espontaneidade documentarizante, à construção criativa de não lugares e às reminiscências do road movie na construção de uma série de paisagens da não inclusão. Eles acabam por associar o campo e a cidade na qualidade de espaços de exploração do operário, tensionados por uma fugaz possibilidade de liberdade.

\section{Considerações finais}

A partir do exposto, podemos entender a relação entre campo/interior e cidade/ capital sob diferentes abordagens. Segundo Bernardet (1980: 147), "conforme a posição assumida diante do mundo rural, a cidade e a desagregação que ela provoca podem ser vistas de modo negativo ou positivo". Os filmes de Trapero 
debatidos, com especial ênfase a Mundo grúa, nos apresentam diferentes formas de entender tais regiões, atentando em particular para o debate de uma visibilidade aos espaços e populações excluídas, a coexistência de referências narrativas e para a construção de modalidades daquilo que denominamos de não lugares. Em oposição aos não lugares de Augé, a prática espacial aqui debatida colabora exatamente para a criação de uma identidade em espaços e práticas de fronteira. Num contexto de desdobramentos do neoliberalismo, globalização e aumento da crise econômica, os próprios limites da ideia de nação estavam socialmente em pauta na Argentina.

As reatualizações das fronteiras narrativas e imaginárias entre cidade e campo no cinema acompanham a dinâmica mais ampla de redefinição do nacional, constituindo-se como espaço privilegiado para vislumbrar processos que ainda não tomaram forma social definitiva. No caso do cinema argentino, como visto, nota-se a criação de brechas, ou vislumbres dos interstícios cotidianos da cidade e do campo, que podem ser pensados como criações de um saber social sobre a crise (PAGE, 2009), explicitações da diferença cinematográfica ante à realidade política do período (ANDERMANN, 2015), ou então uma estetização que rompe carapuças e exterioriza novas significações, trazendo à tona gestos sociais latentes (COMOLLI, 1997). São também alegorias das relações entre modernidade e tradição que se reconfiguram num período turbulento. Talvez seja necessário aprofundar sua interpretação nos termos de alegorias das negociações acerca da nação, cujas representações recorrem à reconstrução das relações entre campo e cidade, espaços que não deixam de ser balizas do próprio processo de modernização. A realocação imaginária do campo-cidade promovida pelo western e pela obra de John Ford já anunciava, desde o início do século XX, a avassaladora importância do tema em contextos de transformações das relações capitalistas e das construções imaginárias do nacional. Na passagem para o século XXI, os paralelos campo-cidade propostos por Mundo grúa, culminando com ambígua fagulha de utopia, colocaram-se como ribeira particular, num contexto mais amplo de globalização e afirmação de identidades transnacionais, enfatizado por Denilson Lopes e Andréa França, cada um a sua maneira, a partir do debate das noções de paisagem transcultural e paisagem fronteiriça, referidos anteriormente.

No cinema de Trapero, as repaginações se dão na cidade, com o gosto por espaços físicos e humanos excluídos, e no campo, com as tensões entre a retomada saudosista das tradições interioranas e a tomada de paisagens áridas como projeção da não inserção, embora sem negar reminiscências utópicas. Resta-nos colocar a construção criativa de não lugares como prática de fronteira, que concentra redefinições narrativas e sociais, tendo por palco as próprias redefinições das relações entre campo e cidade. Talvez possamos falar, no caso de Mundo grúa, em paisagens da não inserção, com suas reminiscências do road movie, o leve sotaque documentarizante e os não lugares, que promovem uma união crítica não destituída de diluição, do campo-cidade, sob os ecos mais amplos de reformulação das construções do nacional e das relações centro-periferia. A partir desses traços temáticos e formais, Mundo grúa parece ecoar uma identidade intersticial bastante particular, alocada num campo de tensões mais amplo, composto por filmes argentinos da época com propostas em diferentes regimes de interstícios, como aqueles de Carlos Sorín (Historias mínimas e EI camino de San Diego), de Adrián Caetano (Bolivia) ou deste com Bruno Stagnaro (Pizza, birra, faso).

A referida riqueza intersticial de Mundo grúa, sob o ponto de vista temático e do próprio ato cinematográfico, por sua vez, aponta para um campo interpretativo ainda mais amplo, a ser explorado. Podem-se encontrar ecos, por exemplo, junto ao guarda-chuva conceitual da noção de espaço praticado, tal como colocado por Certeau em A invenção do cotidiano. As configurações em trânsito, tais como propostas por Mundo grúa, passam-se por uma espécie 
${ }^{14}$ Trata-se de apropriações anônimas, associadas a táticas de disfarce e camuflagem, por meio de uma criatividade tática e bricoladora, que se reapropria dos elementos disseminados pelos grandes poderes, utilizando-os a partir de novos significados. de caça não autorizada ${ }^{14}$ (CERTEAU, 1998: 38), ou braconagem, garimpando elementos narrativos e culturais não vistos, mesclados a referências já vistas, desdobrando-se numa nova geografia do cidade-campo a partir de fins dos anos 1990. O potencial subversivo do gesto, porém, não deixa de ser eclipsado por presenças da narrativa clássica, tendo em Mundo grúa um cotejo particular, que o coloca como exemplo paradigmático de cinema dos interstícios físicos e narrativos, praticado no contexto do nuevo cine argentino.

\section{Referências}

AGUILAR, G. Otros mundos: un ensayo sobre el nuevo cine argentino. Buenos Aires: Santiago Arcos, 2006.

ANDERMANN, J. Nuevo Cine Argentino. Buenos Aires: Paidós, 2015.

AUGÉ, M. Não lugares: introdução a uma antropologia da hipermodernidade. São Paulo: Papirus, 1994.

BECEYRO, R. et al. Estética del cine, nuevos realismos, representación (Debate sobre el nuevo cine argentino). Punto de vista, San Luís Potosí, n. 67, p. 1-9, ago. 2000.

BERNARDET, J.-C. A cidade e o campo: notas iniciais sobre a relação entre a cidade e o campo no cinema brasileiro. In: ANDRADE, R. et al. Cinema brasileiro: 8 estudos. Rio de Janeiro: MEC; Embrafilme; Funarte, 1980.

BOLIVIA. Direção e produção: Adrián Caetano. Intérpretes: Freddy Flores, Rosa Sánchez, Oscar Bertea e Enrique Liporace. Roteiro: Adrián Caetano e Romina Lanfranchini. Buenos Aires: Fundación PROA, 2001. (75 min), black and white., color., $35 \mathrm{~mm}$.

BORGONDI, L.; GUZMÁN, V. Márgenes y periferia en la representación de lo social en el Nuevo Cine Argentino. In: LUSNICH, A. L.; PIEDRAS, P. (Org.). Una historia del cine político y social en Argentina (1969-2009). Buenos Aires: Nueva Livrería, 2011. p. 575-607.

CARANCHO. Direção: Pablo Trapero. Produção: Pablo Trapero. Intérpretes: Ricardo Darín, Martina Gusman, Carlos Weber e José Luis Arias. Roteiro: Alejandro Fadel, Martín Mauregui, Santiago Mitre e Pablo Trapero. Buenos Aires: Matanza Cine, 2010. (107 $\mathrm{min}$ ), son., color., $35 \mathrm{~mm}$.

CARLOS, A. F. A. O espaço urbano. São Paulo: Contexto, 2004.

CASTELLS, E. End of millennium. Oxford: Blackwell, 1998.

CERTEAU, M. de. A invenção do cotidiano: artes do fazer. Petrópolis: Vozes, 1998.

COMOLLI, J. L. A cidade filmada. Cadernos de Antropologia e Imagem: a cidade em imagens, Rio de Janeiro, v. 4, p. 148-157, 1997.

DEREN, M. Cinema: o uso criativo da realidade. Devires, Belo Horizonte, v. 9, n. 1, p. 128-149, jan./jun. 2012.

EL BONAERENSE. Direção: Pablo Trapero. Produção: Martina Gusman e Pablo Trapero. Intérpretes: Jorge Román, Mimí Ardú, Darío Levy e Hugo Anganuzzi. Roteiro: Nicolas Gueilburt, Ricardo Ragendorfer, Dodi Shoeuer, Pablo Trapero e Daniel Valenzuela. Buenos Aires: Pablo Trapero Producciones, 2002. (105 min), son., color., $35 \mathrm{~mm}$. 
EL CAMINO DE San Diego. Direção e roteiro: Carlos Sorín. Produção: Óscar Kramer e Hugo Sigman. Intérpretes: Ignácio Benítez, Carlos Wagner La Bella, Paola Rotela e Silvina Fontelles. Roteiro: Carlos Sorín. Buenos Aires: Guacamole Films, 2006. (98 min), son., color., $35 \mathrm{~mm}$.

EL CLAN. Direção: Pablo Trapero. Produção: Agustín Almodóvar, Pedro Almodóvar, Esther Garcia, Matías Mosteirín, Hugo Sigman e Pablo Trapero. Intérpretes: Guillermo Francella, Peter Lanzani, Lili Popovich e Gastón Cocchiarale. Roteiro: Julian Loyola, Esteban Student e Pablo Trapero. Buenos Aires: Matanza Cine, 2015. (108 min), son., color., digital.

ELEFANTE BLANCO. Direção: Pablo Trapero. Produção: Juan Pablo Galli, Juan Gordon, Juan Vera, Alejandro Cacetta e Pablo Trapero. Intérpretes: Ricardo Darín, Jéremie Renier e Martina Gusman. Roteiro: Alejandro Fadel, Martín Mauregui, Santiago Mitre e Pablo Trapero. Buenos Aires: Matanza Cine, 2012. (105 min), son., color.

FAMILIA RODANTE. Direção: Pablo Trapero. Produção: Robert Bevan, Donald Ranvaud e Pablo Trapero. Intérpretes: Graciana Chironi, Nicolás López, Liliana Capurro e Ruth Dobel. Roteiro: Pablo Trapero. Buenos Aires: Matanza Cine, 2004. (103 min), son., color., $35 \mathrm{~mm}$.

FRANÇA, A. Paisagens fronteiriças no cinema contemporâneo. Alceu, Rio de Janeiro, v. 2, n. 4, p. 61-75, jan./jun. 2002. Disponível em: <http://bit.ly/2jaQnxc>. Acesso em: 7 jul. 2015.

HISTORIAS MÍNIMAS. Direção: Carlos Sorín. Produção: Martin Bardi. Intérpretes: Javier Lombardo, Antonio Benedicti, Javiera Bravo e Julia Solomonoff. Roteiro: Pablo Solarz. Buenos Aires: Guacamole Films, 2002. (92 min), son., color., $35 \mathrm{~mm}$.

LA CIÉNAGA. Direção e roteiro: Lucrecia Martel. Produção: Lila Stantic. Intérpretes: Mercedes Morán, Graciela Borges, Martín Adjemián e Leonora Balcarce. Buenos Aires: 4k Films, 2001. (103 min), son., color., 35 mm.

LEFEBVRE, H. A revolução urbana. Belo Horizonte: UFMG, 1999.

. De lo rural a lo urbano. Barcelona: Edicións 62, 1978.

LEONERA. Direção: Pablo Trapero. Produção: Youngjoo Suh e Pablo Trapero. Intérpretes: Martina Gusman, Elli Medeiros e Rodrigo Santoro. Roteiro: Alejandro Fadel, Martín Mauregui, Santiago Mitre e Pablo Trapero. Buenos Aires: Matanza Cine, 2008. (113 min), son., color., $35 \mathrm{~mm}$.

LOPES, D. Paisagens transculturais. In: LOPES, D.; FRANÇA, A. (Org.). Cinema, globalização e interculturalidade. Chapecó: Unichapecó, 2010. p. 91-108.

MUNDO GRÚA. Direção: Pablo Trapero. Produção: Lita Stantic e Pablo Trapero. Intérpretes: Luis Margani, Adriana Aizemberg, Daniel Valenzuela, Roly Serrano e Federico Esquerro. Roteiro: Pablo Trapero. Buenos Aires: Cinematografica Producciones, 1999. (90 min), son., black and white., $35 \mathrm{~mm}$.

NACIDO Y CRIADO. Direção: Pablo Trapero. Produção: Douglas Cummins e Pablo Trapero. Intérpretes: Fernanda de Almeida, Federico Esquerro, Martina Gusman e Tomás Lipan. Roteiro: Mario Rulloni e Pablo Trapero. Buenos Aires: Matanza Cine, 2006. (100 min), son., color.

ODIN, R. Filme documentário, leitura documentarizante. Significação, São Paulo, ano 39, n. 37, p. 10-30, 2012. 
OUBIÑA, D. Between breakup and tradition: recent Argentinean cinema. Senses of Cinema, Melbourne, n. 31, abr. 2004. Disponível em: <http://bit.ly/2ibGKA9> Acesso em: 1 jul. 2016.

PAGE, J. Crisis and capitalism in contemporary Argentine cinema. Durham; London: Duke University, 2009.

PIZZA, BIRRA, FASO. Direção: Adrián Caetano e Bruno Stagnaro. Produção: Bruno Stagnaro. Intérpretes: Héctor Anglada, Jorge Sesán, Pamela Jordán e Adrián Yospe. Roteiro: Adrián Caetano e Bruno Stagnaro. Buenos Aires: Palo y a La Bolsa Cine, 1998. (76 min), son., black and white., digital.

SARLO, B. Tiempo presente. Buenos Aires: Siglo XXI, 2001.

VERARDI, M. Representaciones familiares en el Nuevo Cine Argentino. In: JORNADAS DE JÓVENES INVESTIGADORES, 4., 2007, Buenos Aires. Anais... Buenos Aires: Instituto de Investigaciones Gino Germani, 2007.

WILLIAMS, R. Marxismo e literatura. Rio de Janeiro: Zahar, 1979. Letras, 1989.

O campo e a cidade: na história e na literatura. São Paulo: Companhia das 